\title{
Acquisition Pricing and Inventory Decisions on Dual-Source Spare-Part System with Final Production and Remanufacturing
}

\author{
Yancong Zhou, ${ }^{1}$ Xudong Guo, ${ }^{2}$ and Xiaochen Sun ${ }^{3}$ \\ ${ }^{1}$ School of Information Engineering, Tianjin University of Commerce, Tianjin 300134, China \\ ${ }^{2}$ Tourism and Historical Culture College, Zhaoqing University, Zhaoqing 526061, China \\ ${ }^{3}$ Department of Mathematics, Tianjin University, Tianjin 300072, China
}

Correspondence should be addressed to Yancong Zhou; zycong78@126.com

Received 27 March 2016; Accepted 10 May 2016

Academic Editor: Guo Chen

Copyright (C) 2016 Yancong Zhou et al. This is an open access article distributed under the Creative Commons Attribution License, which permits unrestricted use, distribution, and reproduction in any medium, provided the original work is properly cited.

\begin{abstract}
The life spans of durable goods are longer than their warranty periods. To satisfy the service demand of spare parts and keep the market competition advantage, enterprises have to maintain the longer inventory planning of spare parts. However, how to obtain a valid number of spare parts is difficult for those enterprises. In this paper, we consider a spare-part inventory problem, where the inventory can be replenished by two ways including the final production order and the remanufacturing way. Especially for the remanufacturing way, we consider the acquisition management problem of used products concerning an acquisition pricing decision. In a multiperiod setting, we formulate the problem into a dynamic optimization problem, where the system decisions include the final production order and acquisition price of used products at each period. By stochastic dynamic programming, we obtain the optimal policy of the acquisition pricing at each period and give the optimal policy structure of the optimization problem at the first period. Then, a recursion algorithm is designed to calculate the optimal decisions and the critical points in the policy. Finally, the numerical analyses show the effects of demand information and customer's sensitive degree on the related decisions and the optimal cost.
\end{abstract}

\section{Introduction}

With the improvement of market competition, customers have larger difficulty in distinguishing the products with similar functions. In addition to the price, they also have to consider more other factors. In those factors, after-sale service is the most important indicator, especially for durable products, such as automobile, computer, household appliances, and engineering equipment.

Current enterprises concern more the after-sale service within the regular warranty period. However, for durable products, the warranty period is much less than the product life span. For example, the warranty period of refrigerator is less than three years, but the product life is more than 10 years. And the probability of the product failure outside the warranty period is larger. When a failure occurs, although the product is outside the warranty period, the user still hopes the enterprise provides related services. However, if the enterprise cannot effectively help the user to solve the problem, it will have a negative impression of their products and directly affect the consumers' choice at the next time purchase option. For some personalized products, users are more dependent on the services provided by the manufacturer, ignoring the after-sale service outside the regular warranty period due to more serious results, which is showed by Nagler [1]: "you buy a car and eight years later cannot get it serviced for a reasonable price because the manufacturer has discontinued a particular part, you will remember it when you buy your next vehicle". Besides, for the necessity of keeping the competitive advantage of enterprises, some countries also have obliged enterprises to provide the service at outside the regular warranty period, for example, for 15 years in case of automobiles in Germany. Therefore, providing the extended after-sale service will be a trend practical issue, and the related research is important. 
In current actual operations, the shortage of spare parts is the most difficult problem for providing after-sale service at outside the regular warranty period. This especially holds for durable products, because the production line has been closed. The shortage of spare parts will improve the service cost and brings a long waiting time, which results in a lower user's satisfaction and vanishes the action of providing aftersale service outside the regular warranty period. Because of no valid ways of replenishing inventory, the higher inventory or operation cost may be the major reason that enterprises do not want to provide the after-sale service outside the regular warranty period. Thus, how to replenish the inventory of spare part is the key problem for the extended after-sale service outside the regular warranty period.

The inventory replenishment problem of spare parts had became a concerned problem in the field of management and engineering sciences (Armstrong and Atkins [2], Bruggeman and van Dierdonck [3], Dhakar et al. [4], and Díaz and Fu [5]). The traditional replenishment mainly includes two ways: (i) producing enough spare parts before closing the regular production line and (ii) extra producing or ordering when the inventory is not enough. However, the first way has the high inventory cost and risk because of a very long service period; and the latter does not need to hold a high inventory, but it is discontinuous and has a high setup cost. The two ways are not enough to support the after-sale service outside the regular warranty period. Therefore, a kind of way with lower cost and continuous replenishment is necessary for the after-sale service outside the regular warranty period. Remanufacturing has been proved to be a good resource reusing way. For after-sale service, remanufacturing used products also can provide the necessary spare parts, and the related cost is lower and the replenishment process is also continuous. Fleischmann et al. [6] showed that product recovery can be as a major source of spare parts. Teunter and Fortuin [7] provided a case study, where spare parts can be replenished by recovering used products. However, remanufacturing also have shortcomings, such as higher uncertainty, and are constrained by the history of selling quantity of the product, so the traditional ways are still to be valid and necessary. Thus, how to integrate multiways to replenish the inventory of spare parts is important.

On the optimal acquisition problem of after-sale spare parts, Fortuin [8] firstly studied the size of the final production lot for the regular production. Teunter and Fortuin [9] extended the approach in Fortuin to a more complicated version. Cattani and Souza [10] considered the time of starting the final lot. van Kooten and Tan [11] provided a numerical method for determining the final order by Markov chain. The above papers only considered the final lot decision. Teunter and Klein Haneveld [12] consider a combination of final order and extra production order and gave an order-up-to policy. Inderfurth and Mukherjee [13] considered the combination of three ways of the spare parts' acquisition, that is, (i) the final lot of regular production, (ii) performing extra production runs until the end of service, and (iii) using remanufacturing to gain spare parts from used products. The decision is to find out the optimal combination of these three options. The model is modeled by decision tree and solved by a heuristic method based on stochastic dynamic programming. Pourakbar et al. [14] considered the determination problem of the optimal time to switch, where there are multioptions including the final order and repair policy, and the repairing component can be substituted by a new product. However, few papers consider the acquisition management problem of used products in a spare-part inventory system. The problem is important for ensuring the stability of the remanufacturing process of used products, and it is considered in this paper.

In a spare-part inventory system, the accurate demand information is important, which can reduce safety stock and thus might reduce cost without reducing service levels. A manager may need to focus on the development of information technology for effective inventory management. We know that, under a communication link technology, typically electronic data interchange (EDI), a vendor-managed inventory (VMI) is more effective to plan inventory and place orders. For example, Bourland et al. [15] investigated the operational problem of the tradeoff between communication (i.e., EDI) and inventory. They assumed a fixed cost of acquiring timely demand information and examined how the firm to adjust its inventory behavior. And information technology has enabled some researches to be more proactive and obtain advance demand information in addition to improving demand forecast, such as Gallego and Özer (2001 [16], 2003 [17]) and Özer and Wei (2004 [18]); they incorporated advance demand information into periodic-review inventory control problems. Although the main methods for forecasting demand are still statistical methods, such as moving average and exponential smoothing (also see Axsater, 2006 [19]), under more advanced information technologies (such as Radio-Frequency Identification (RFID), cloud computing, and Internet of Things), firms might obtain more in advance and more accurate information, such as the real-time status of one product, historical sales data, customers' position, the correlation between the historical service data, the using environment of the product, and customers' types. These possibilities also enable firms to change the operations policy, such as making a better and longer spare-part inventory planning. Therefore, we can consider a multiperiod spare-part inventory problem under the existing of remanufacturing.

In this paper, we will consider the inventory decisions problem in a multisource spare-part system, where we adopt the final production order and remanufacturing ways to replenish spare parts. The final production order provides the initial inventory of spare parts; then, the inventory is continuously replenished by collecting and remanufacturing used products. Under the setting, the manager needs to determine the optimal final production order and acquisition price of collecting used products.

The rest of this paper is organized as follows. In Section 2, we give the problem description and formulation. Section 3 provides the optimal acquisition pricing policy. Furthermore, we analyze the optimal size of the final production order and the acquisition pricing at the first period in Section 4. In Section 5, we propose an algorithm for the parameters in optimal policy structures. Numerical examples are provided in Section 6. Finally, we conclude our paper in Section 7. 


\section{Problem Description and Formulation}

We consider an inventory system with single spare part and two replenishment ways, including the final production order and remanufacturing. The final production order only needs to be determined at the time of closing production line, which maintains the demand of the regular warranty period. To satisfy the demand in an extended warranty period, especially for outside the regular warranty period, the enterprise starts an acquisition and remanufacturing planning of used products, that is, by collecting and remanufacturing the used products into serviceable components and furthermore satisfying the demand in the service period. For controlling the return quantity of used products, the enterprise will provide an incentive for users which may be a cash payment. We call it acquisition price. A finite period setting will be considered in the following. Without loss of generality, the length of a period is assumed to be one, and the periods are numbered by $k=1,2, \ldots, N$.

Let $\tau_{k}$ denote the acquisition price at period $k$ and $\xi_{k}\left(\tau_{k}\right)$ denote the returned quantity when the acquisition price is $\tau_{k}$; it is defined as the following form:

$$
\xi_{k}\left(\tau_{k}\right)=\mu_{k}\left(\tau_{k}\right)+\varepsilon_{k},
$$

where $\mu_{k}\left(\tau_{k}\right)=\alpha+\beta \tau_{k}$ and $\varepsilon_{k}$ is a random factor with support $\left[a_{k}, b_{k}\right]$ and zero mean value. $\mu_{k}\left(\tau_{k}\right)$ is the expected quantity of returned products under the given acquisition price $\tau_{k}$. This linear form is similar to the linear demand function, and the latter is frequently used in many studies (e.g., Federgruen and Heching [20], Simchi-Levi et al. [21], and Sun et al. [22]). We assume that the supply capacity of returned products is unlimited, and all returned products can be remanufactured into serviceable parts. And the remanufacturing process has no production loss, and the unit returned product will yield the unit serviceable part.

All demands of serviceable parts at different periods are stochastic and independent of each other. Because demands and supplies are stochastic, both the inventory shortage and surplus status are possible. The unsatisfied demands need to be backlogged and incur the inventory shortage cost. Further, all surplus will be transferred into the next period and incur the inventory holding cost.

The sequence of system events is given as follows. First, the firm determines the size of the final production order and acquisition price at the beginning of the planning horizon. From the second period to the $N$ th period, the firm only determines the acquisition price level at the period. Then, within each period, the firm acquires used products from users and remanufactures returned products into serviceable parts and reviews the inventory state of the serviceable part and calculates the related costs. The holding inventory cost can be obtained by the multiplication of the unit holding cost and the quantity of serviceable parts of entering the inventory, which also means that even if one spare part is put into the inventory and taken away in the same period, its cost is still calculated.

The optimization problem is to find the optimal final production order and the optimal acquisition price policies of different periods so that the total inventory and acquisition costs can be minimized.

From the sequence of system events, we have the following state equation of the dynamic system:

$$
I_{k+1}= \begin{cases}I_{k}+\xi_{k}\left(\tau_{k+1}\right)-D_{k+1}, & k \geq 1, \\ i_{0}+Q+\xi_{1}\left(\tau_{1}\right)-D_{1}, & k=0 .\end{cases}
$$

For period $k, k \geq 2$, when the initial inventory level is $I_{k-1}$ and the acquisition price is $\tau_{k}$, the cost function at the period is given as follows:

$$
\begin{aligned}
g_{k}\left(I_{k-1}, \tau_{k}\right)= & \tau_{k} \xi_{k}\left(\tau_{k}\right)+h\left(\left(I_{k-1}\right)^{+}+\xi_{k}\left(\tau_{k}\right)\right) \\
& +q\left(D_{k}-I_{k-1}-\xi_{k}\left(\tau_{k}\right)\right)^{+},
\end{aligned}
$$

where $(x)^{+}=\max \{x, 0\}$. The first term of the above equation is the acquisition cost, and the second term is the inventory holding cost, and the third term is the penalty cost of the shortage parts. Especially for the first period, there is the final production order and the cost function is given as follows:

$$
\begin{aligned}
g_{1}\left(i_{0}, Q, \tau_{1}\right)= & \tau_{1} \xi_{1}\left(\tau_{1}\right)+h\left(i_{0}+Q+\xi_{1}\left(\tau_{1}\right)\right) \\
& +q\left(D_{1}-i_{0}-Q-\xi_{1}\left(\tau_{1}\right)\right)^{+} .
\end{aligned}
$$

Let $\pi$ denote a feasible policy and be defined by $\pi=$ $\left\{\left(Q, \tau_{1}, \ldots, \tau_{N}\right) \mid Q \geq 0, \tau_{k} \in\left[0, \tau_{u}\right]\right\}$. Therefore, for a given initial inventory level $i_{0}$ and a feasible policy $\pi$, the total cost of the whole system is

$$
W\left(i_{0}, \pi\right)=g_{1}\left(i_{0}, Q, \tau_{1}\right)+\sum_{k=2}^{N} g_{k}\left(I_{k-1}, \tau_{k}\right),
$$

where we assume the end cost at the planning horizon to be zero.

Let $\Pi$ denote the set including all feasible policies, so there is $\pi \in \Pi$. The optimization problem in this paper is as follows: for a given initial inventory level $i_{0}$, to find an optimal policy $\pi^{*}=\left(Q^{*}, \tau_{1}^{*}, \ldots, \tau_{N}^{*}\right)$ so that the expectation value of the total cost in (5) is minimum; that is,

$$
W\left(i_{0}, \pi^{*}\right)=\min _{\pi \in \Pi}\left\{E\left[W\left(i_{0}, \pi\right)\right]\right\} .
$$

We call $Q^{*}$ the optimal final production order and $\tau_{k}^{*}$ the optimal acquisition price at the period $k$. In the following, we will give the dynamic programming equation of solving the optimization problem.

Let $i_{k-1}$ denote the realized inventory state at the beginning of the period $k$. And for $k \geq 2$, let

$$
W_{k}\left(i_{k-1}, \pi_{k}\right)=E\left[\sum_{j=k}^{N} g_{j}\left(I_{j-1}, \tau_{j}\right) \mid I_{k-1}=i_{k-1}\right],
$$

and for $k=1$, let

$$
W_{1}\left(i_{0}, \pi_{1}\right)=E\left[g_{1}\left(i_{0}, Q, \tau_{1}\right)\right]+E\left[\sum_{j=2}^{N} g_{j}\left(I_{j-1}, \tau_{j}\right)\right] \text {. }
$$


Furthermore, define the following optimal value function:

$$
W_{k}\left(i_{k-1}\right)=\min _{\pi_{k}}\left\{W_{k}\left(i_{k-1}, \pi_{k}\right)\right\}, \quad 1 \leq k \leq N+1,
$$

so $W_{1}\left(i_{0}\right)=W\left(i_{0}, \pi^{*}\right)$. In the above equations, $\pi_{k}=\left(\tau_{k}, \ldots\right.$, $\left.\tau_{N}\right)$ for $k \geq 2$ and $\pi_{1}=\left(Q, \tau_{1}, \ldots, \tau_{N}\right)$ for $k=1$. Therefore, the dynamic programming equations of the optimization problem in (6) are given as follows:

$$
\begin{aligned}
& W_{1}\left(i_{0}\right)=\min _{Q \geq 0, \tau_{1} \in\left[0, \tau^{u}\right]}\left\{E\left[g_{1}\left(i_{0}, Q, \tau_{1}\right)\right]\right. \\
& \left.\quad+E\left[W_{2}\left(i_{0}+Q+\xi_{1}\left(\tau_{1}\right)-D_{1}\right)\right]\right\}, \\
& W_{k}\left(i_{k-1}\right)=\min _{\tau_{k} \in\left[0, \tau^{u}\right]}\left\{E\left[g_{k}\left(i_{k-1}, \tau_{k}\right)\right]\right. \\
& \left.\quad+E\left[W_{k+1}\left(i_{k-1}+\xi_{k}\left(\tau_{k}\right)-D_{k}\right)\right]\right\}, \quad 2 \leq k \leq N \\
& W_{N+1}\left(i_{N}\right)=0 .
\end{aligned}
$$
sions.

In the following section, we will analyze the optimal deci-

\section{Optimal Acquisition Pricing for $k \geq 2$}

In this section, we will give the optimal acquisition pricing decision $\tau_{k}^{*}$ for $k \geq 2$. From the second equation in (10), we define

$$
\begin{aligned}
H_{k}\left(i_{k-1}, \tau_{k}\right)= & E\left[g_{k}\left(i_{k-1}, \tau_{k}\right)\right] \\
& +E\left[W_{k+1}\left(i_{k-1}+\xi_{k}\left(\tau_{k}\right)-D_{k}\right)\right] .
\end{aligned}
$$

To analyze the properties of $H_{k}\left(i_{k-1}, \tau_{k}\right)$, we firstly give the following lemmas.

Lemma 1. If the function $h(x)$ is convex in $x$, then the function $g(x, y)=E[h(x+a y-D)]$ is jointly convex in $x$ and $y$, where $D$ is a stochastic variable with the cumulative distribution function $F(\cdot)$.

Proof. For any given $z_{1}=\left(x_{1}, y_{1}\right)$ and $z_{2}=\left(x_{2}, y_{2}\right)$ and $\theta \epsilon$ $[0,1]$, we have

$$
\begin{aligned}
& g\left(\theta z_{1}+(1-\theta) z_{2}\right)=g\left(\theta x_{1}+(1-\theta) x_{2}, \theta y_{1}+(1\right. \\
& \left.\quad-\theta) y_{2}\right)=E\left[h \left(\theta x_{1}+(1-\theta) x_{2}\right.\right. \\
& \left.\left.\quad+a\left(\theta y_{1}+(1-\theta) y_{2}\right)-D\right)\right]=\int_{-\infty}^{+\infty} h\left(\theta x_{1}\right. \\
& \quad+(1-\theta) x_{2}+a\left(\theta y_{1}+(1-\theta) y_{2}\right) \\
& \quad-z) d F(z) \\
& \quad=\int_{-\infty}^{+\infty} h\left(\theta\left(x_{1}+a y_{1}-z\right)\right. \\
& \left.\quad+(1-\theta)\left(x_{2}+a y_{2}-z\right)\right) d F(z)
\end{aligned}
$$

$$
\begin{aligned}
& \leq \theta \int_{-\infty}^{+\infty} h\left(x_{1}+a y_{1}-z\right) d F(z)+(1-\theta) \\
& \cdot \int_{-\infty}^{+\infty} h\left(x_{2}+a y_{2}-z\right) d F(z)=\theta E\left[h \left(x_{1}\right.\right. \\
& \left.\left.+a y_{1}-z\right)\right]+(1-\theta) E\left[h\left(x_{2}+a y_{2}-z\right)\right] \\
& =\theta g\left(z_{1}\right)+(1-\theta) g\left(z_{2}\right) .
\end{aligned}
$$

Therefore, $g(x, y)$ is convex in $x$ and $y$.

Lemma 2. If $f(x, y)$ is jointly convex in $x$ and $y$ and $C$ is a convex set, then $g(x)=\min _{y \in C} f(x, y)$ is also convex in $x$.

Proof. For the proof of the lemma, please see page 84 in Boyd and Vandenberghe [23]. $\left.\left.\tau_{k}\right)\right]$

In the following, we analyze the properties of $E\left[g_{k}\left(i_{k-1}\right.\right.$,

Theorem 3. The period cost function $E\left[g_{k}\left(i_{k-1}, \tau_{k}\right)\right]$ in (3) has the following properties: (a) $E\left[g_{k}\left(i_{k-1}, \tau_{k}\right)\right]$ is convex in $i_{k-1}$ and $\tau_{k}$; (b) $E\left[g_{k}\left(i_{k-1}, \tau_{k}\right)\right]$ is supermodular in $i_{k-1}$ and $\tau_{k}$.

Proof. We firstly prove part (a). It is obvious that the function $\max \{-x, 0\}$ is convex. From (1), there is $\xi_{k}\left(\tau_{k}\right)=\rho_{k} \alpha+\beta \rho_{k} \tau_{k}$. And by Lemma 1 , we easily know that $E\left[\max \left\{D_{k}-x-\right.\right.$ $\left.\left.\xi_{k}\left(\tau_{k}\right), 0\right\}\right]$ is convex in $x$ and $\tau_{k}$. Other parts in $E\left[g_{k}\left(i_{k-1}, \tau_{k}\right)\right]$ are convex obviously. So part (b) holds.

For part (b), for any $x_{1} \geq x_{2}$ and $\tau_{k}^{1} \geq \tau_{k}^{2}$, we have

$$
\begin{aligned}
E[ & \left.g_{k}\left(x_{1}, \tau_{k}^{1}\right)\right]+E\left[g_{k}\left(x_{2}, \tau_{k}^{2}\right)\right]-E\left[g_{k}\left(x_{1}, \tau_{k}^{2}\right)\right] \\
& -E\left[g_{k}\left(x_{2}, \tau_{k}^{1}\right)\right]=q\left(E\left[\left(D_{k}-x_{1}-\xi_{k}\left(\tau_{k}^{1}\right)\right)^{+}\right]\right. \\
& +E\left[\left(D_{k}-x_{2}-\xi_{k}\left(\tau_{k}^{2}\right)\right)^{+}\right] \\
& -E\left[\left(D_{k}-x_{1}-\xi_{k}\left(\tau_{k}^{2}\right)\right)^{+}\right] \\
& \left.-E\left[\left(D_{k}-x_{2}-\xi_{k}\left(\tau_{k}^{1}\right)\right)^{+}\right]\right) .
\end{aligned}
$$

Let $g(y, d)=\left(d-y-x_{1}\right)^{+}-\left(d-y-x_{2}\right)^{+}$, easily knowing that $g(y, d)$ is nondecreasing in $y$. From $\tau_{k}^{1} \geq$ $\tau_{k}^{2}$, there is $\xi_{k}\left(\tau_{k}^{1}\right) \geq_{s t} \xi_{k}\left(\tau_{k}^{2}\right)$. And from Ross [24], we have $E\left[g\left(\xi_{k}\left(\tau_{k}^{1}, D_{k}\right)\right)\right] \geq E\left[g\left(\xi_{k}\left(\tau_{k}^{2}, D_{k}\right)\right)\right]$, so

$$
\begin{gathered}
E\left[g_{k}\left(x_{1}, \tau_{k}^{1}\right)\right]+E\left[g_{k}\left(x_{2}, \tau_{k}^{2}\right)\right]-E\left[g_{k}\left(x_{1}, \tau_{k}^{2}\right)\right] \\
-E\left[g_{k}\left(x_{2}, \tau_{k}^{1}\right)\right] \geq 0 .
\end{gathered}
$$

Therefore, $E\left[g_{k}\left(x_{1}, \tau_{k}\right)\right]$ is supermodular in $x_{1}$ and $\tau_{k}$.

Furthermore, the following theorem gives the properties of the optimal value function and the objective function. 
Theorem 4. The optimal value function $W_{k}\left(i_{k-1}\right)$ in (9) and the objective function $H_{k}\left(i_{k-1}, \tau_{k}\right)$ in (11) have the following properties:

(a) $W_{k+1}\left(i_{k}\right)$ is convex in $i_{k}$ for $k=1,2, \ldots, N$.

(b) $H_{k}\left(i_{k-1}, \tau_{k}\right)$ is convex in $i_{k-1}$ and $\tau_{k}$ for $k=2,3, \ldots, N$.

(c) $H_{k}\left(i_{k-1}, \tau_{k}\right)$ is supermodular in $i_{k-1}$ and $\tau_{k}$ for $k=$ $2,3, \ldots, N$.

Proof. Apply backward recursive method.

When $k=N$, there is always $W_{N+1}\left(i_{N}\right)=0$ for any $i_{N}$, so part (a) holds for $k=N+1$. From (11), there is

$$
H_{k}\left(i_{k-1}, \tau_{k}\right)=E\left[g_{k}\left(i_{k-1}, \tau_{k}\right)\right],
$$

and by Theorem 3 , it is obvious that $H_{k}\left(i_{k-1}, \tau_{k}\right)$ is convex and supermodular in $i_{k-1}$ and $\tau_{k}$.

Assume that the theorem holds for $k=n+1$; that is,

(a) $W_{n+2}\left(i_{n+1}\right)$ is convex in $i_{n+1}$;

(b) $H_{n+1}\left(i_{n}, \tau_{n+1}\right)$ is convex in $i_{n}$ and $\tau_{n+1}$;

(c) $H_{n+1}\left(i_{n}, \tau_{n+1}\right)$ is super-modular in $i_{n}$ and $\tau_{n+1}$.

We need to prove that the theorem still holds for $k=n$. From (10) and (11), we have

$$
W_{n+1}\left(i_{n}\right)=\min _{\tau_{n+1} \in\left[0, \tau^{u}\right]}\left\{H_{n+1}\left(i_{n}, \tau_{n+1}\right)\right\} .
$$

From inductive assumption (b), $H_{n+1}\left(i_{n}, \tau_{n+1}\right)$ is convex in $i_{n}$ and $\tau_{n+1}$, and $\left[0, \tau^{u}\right]$ is a convex set, from Lemma 2 , so $W_{n+1}\left(i_{n}\right)$ is convex in $i_{n}$.

From (11), we have

$$
\begin{aligned}
H_{k}\left(i_{n-1}, \tau_{n}\right)= & E\left[g_{n}\left(i_{n-1}, \tau_{n}\right)\right] \\
& +E\left[W_{n+1}\left(i_{n-1}+\xi_{n}\left(\tau_{n}\right)-D_{n}\right)\right] .
\end{aligned}
$$

Because $W_{n+1}\left(i_{n}\right)$ is convex in $i_{n}$, from Lemma 1 , we have the notion that $E\left[W_{n+1}\left(i_{n-1}+\xi_{n}\left(\tau_{n}\right)-D_{n}\right)\right]$ is convex in $i_{n-1}$ and $\tau_{n}$. And from Theorem 3 , we have the notion that $E\left[g_{n}\left(i_{n-1}, \tau_{n}\right)\right]$ is convex in $i_{n-1}$ and $\tau_{n}$. Therefore, $H_{n}\left(i_{n-1}, \tau_{n}\right)$ is convex in $i_{n-1}$ and $\tau_{n}$.

For the supermodular property in part (c), we firstly prove $E\left[W_{n+1}\left(i_{n-1}+\xi_{n}\left(\tau_{n}\right)-D_{n}\right)\right]$ to be supermodular in $i_{n-1}$ and $\tau_{n}$. Set $H(y)=E\left[W_{k+1}\left(x_{2}+y-D_{k}\right)\right]-E\left[W_{k+1}\left(x_{1}+y-D_{k}\right)\right]$. For any $x_{1} \leq x_{2}$, we have

$$
\begin{aligned}
H & \left(y+x_{2}-x_{1}\right)-H(y) \\
& =\left(E\left[W_{k+1}\left(2 x_{2}+y-x_{1}-D_{k}\right)\right]\right. \\
& \left.-E\left[W_{k+1}\left(x_{2}+y-D_{k}\right)\right]\right) \\
& -\left(E\left[W_{k+1}\left(x_{2}+y-D_{k}\right)\right]\right. \\
& \left.-E\left[W_{k+1}\left(x_{1}+y-D_{k}\right)\right]\right) \\
& =E\left[W_{k+1}\left(2 x_{2}+y-x_{1}-D_{k}\right)\right] \\
& -2 E\left[W_{k+1}\left(x_{2}+y-D_{k}\right)\right] \\
& +E\left[W_{k+1}\left(x_{1}+y-D_{k}\right)\right]
\end{aligned}
$$

Because $W_{n+1}\left(i_{n}\right)$ is convex in $i_{n}, E\left[W_{k+1}\left(i_{n}-D_{k}\right)\right]$ is also convex. Therefore, $H\left(y+x_{2}-x_{1}\right)-H(y) \geq 0$; that is, $H(y)$ is increasing with respect to $y$. For $\tau_{k}^{1} \leq \tau_{k}^{2}$, we easily know that $\xi_{k}\left(\tau_{k}^{1}\right) \leq_{s t} \xi_{k}\left(\tau_{k}^{2}\right)$, so there is $E\left[H\left(\xi_{k}\left(\tau_{k}^{1}\right)\right)\right] \leq E\left[H\left(\xi_{k}\left(\tau_{k}^{2}\right)\right)\right]$; that is,

$$
\begin{aligned}
E\left[W_{k+1}\left(x_{2}+\xi_{k}\left(\tau_{k}^{1}\right)-D_{k}\right)\right] \\
-E\left[W_{k+1}\left(x_{1}+\xi_{k}\left(\tau_{k}^{1}\right)-D_{k}\right)\right] \\
\leq E\left[W_{k+1}\left(x_{2}+\xi_{k}\left(\tau_{k}^{2}\right)-D_{k}\right)\right] \\
\quad-E\left[W_{k+1}\left(x_{1}+\xi_{k}\left(\tau_{k}^{2}\right)-D_{k}\right)\right] .
\end{aligned}
$$

Therefore, $E\left[W_{n+1}\left(i_{n-1}+\xi_{n}\left(\tau_{n}\right)-D_{n}\right)\right]$ is supermodular in $i_{n-1}$ and $\tau_{n}$. And from part (b) in Theorem 3 and (11), $H_{n}\left(i_{n-1}, \tau_{n}\right)$ is supermodular in $i_{n-1}$ and $\tau_{n}$. In summary, the induction method has been completed.

From part (b) in Theorem 4, we know that the optimal solution of $\min _{\tau_{k} \in\left[0, \tau^{u}\right]}\left\{H_{k}\left(i_{k-1}, \tau_{k}\right)\right\}$ is unique, so we can make the following definition:

$$
\tau_{k}\left(i_{k-1}\right)=\arg \min _{\tau_{k} \in\left[0, \tau^{u}\right]}\left\{H_{k}\left(i_{k-1}, \tau_{k}\right)\right\}
$$

For $\tau_{k}\left(i_{k-1}\right)$, we have the following property.

Theorem 5. The optimal solution $\tau_{k}\left(i_{k-1}\right)$ in (20) is decreasing with respect to $i_{k-1}$.

Proof. From part (c) in Theorem 4, we have the notion that $H_{k}\left(i_{k-1}, \tau_{k}\right)$ is supermodular in $i_{k-1}$ and $\tau_{k}$. And according to Puterman [25] (Lemma 4.7.2 in page 94), $\tau_{k}\left(i_{k-1}\right)$ is decreasing with respect to $i_{k-1}$.

Theorem 6. There exists $X_{k}^{u}$ with the following definition:

$$
X_{k}^{u}=\inf \left\{i_{k-1} \mid \tau_{k}\left(i_{k-1}\right)=0\right\} .
$$

Proof. The first-order derivative of $H_{k}\left(i_{k-1}, \tau_{k}\right)$ with respect to $\tau_{k}$ is given as follows:

$$
\begin{aligned}
\frac{\partial H_{k}\left(i_{k-1}, \tau_{k}\right)}{\partial \tau_{k}}= & \alpha+2 \beta \tau_{k}+\beta h-q \beta \\
& +q \beta F\left(i_{k-1}+\alpha+\beta \tau_{k}\right) \\
& +\beta \frac{\partial E\left[W_{k+1}\left(i_{k-1}+\xi_{k}\left(\tau_{k}\right)-D_{k}\right)\right]}{\partial \tau_{k}}
\end{aligned}
$$

For a finite period problem, when the inventory level $i_{k-1}$ at the period $k-1$ is large enough, the shortage cost can be ignored in the following periods, so there is $\partial E\left[W_{k+1}\left(i_{k-1}+\right.\right.$ $\left.\left.\xi_{k}\left(\tau_{k}\right)-D_{k}\right)\right] / \partial \tau_{k}=h$. Therefore, $\partial H_{k}\left(i_{k-1}, \tau_{k}\right) / \partial \tau_{k}>0$; that is, the optimal solution is $\tau_{k}\left(i_{k-1}\right)=0$.

Corollary 7. The optimal acquisition price decision obeys the following decision rule:

$$
\tau_{k}^{*}= \begin{cases}\tau_{k}\left(i_{k-1}\right), & i_{k-1}<X_{k}^{u}, \\ 0, & i_{k-1} \geq X_{k}^{u} .\end{cases}
$$


And if there exists $X_{k}^{l}$ with the following definition

$$
X_{k}^{l}=\sup \left\{i_{k-1} \mid \tau_{k}\left(i_{k-1}\right)=\tau^{u}\right\},
$$

then the optimal acquisition price is

$$
\tau_{k}^{*}= \begin{cases}\tau^{u}, & i_{k-1} \leq X_{k}^{l}, \\ \tau_{k}\left(i_{k-1}\right), & X_{k}^{l}<i_{k-1}<X_{k}^{u}, \\ 0, & i_{k-1} \geq X_{k}^{u},\end{cases}
$$

where $\tau_{k}\left(i_{k-1}\right)$ is the solution of $\partial H_{k}\left(i_{k-1}, \tau_{k}\right) / \partial \tau_{k}=0 . X_{k}^{l}$ is defined in (24), and $X_{k}^{u}$ is defined in (21).

Proof. From the monotonicity of $\tau_{k}\left(i_{k-1}\right)$ in Theorem 5 and the definitions of $X_{k}^{l}$ in (24) and $X_{k}^{u}$ in (21), the corollary is obvious.

\section{Optimal Acquisition Pricing and Final Order}

In this section, we will give the optimal decisions $Q^{*}$ and $\tau_{k}^{*}$ for $k=1$. From the first equation in (10), we define

$$
\begin{aligned}
H_{1}\left(i_{0}, Q, \tau_{1}\right)= & E\left[g_{1}\left(i_{0}, Q, \tau_{1}\right)\right] \\
& +E\left[W_{2}\left(i_{0}+Q+\xi_{1}\left(\tau_{1}\right)-D_{1}\right)\right] .
\end{aligned}
$$

Let $y_{1}=i_{0}+Q_{1}$ denote the inventory level of serviceable parts after replenishing. Therefore, we have $E\left[g_{1}\left(0, y_{1}, \tau_{1}\right)\right]=$ $E\left[g_{1}\left(i_{0}, Q, \tau_{1}\right)\right]$, and, further, there is

$$
\begin{aligned}
H_{1}\left(i_{0}, Q, \tau_{1}\right)= & H_{1}\left(0, y_{1}, \tau_{1}\right) \\
= & E\left[g_{1}\left(0, y_{1}, \tau_{1}\right)\right] \\
& +E\left[W_{2}\left(y_{1}+\xi_{1}\left(\tau_{1}\right)-D_{1}\right)\right] \\
= & \tau_{1} \xi_{1}\left(\tau_{1}\right)+h\left(y_{1}+\xi_{1}\left(\tau_{1}\right)\right) \\
& +q\left(D_{1}-y_{1}-\xi_{1}\left(\tau_{1}\right)\right)^{+} \\
& +E\left[W_{2}\left(y_{1}+\xi_{1}\left(\tau_{1}\right)-D_{1}\right)\right] .
\end{aligned}
$$

For convenience, let $H\left(y_{1}, \tau_{1}\right)=H_{1}\left(0, y_{1}, \tau_{1}\right)$; that is,

$$
\begin{aligned}
H\left(y_{1}, \tau_{1}\right)= & \tau_{1} \xi_{1}\left(\tau_{1}\right)+h\left(y_{1}+\xi_{1}\left(\tau_{1}\right)\right) \\
& +q\left(D_{1}-y_{1}-\xi_{1}\left(\tau_{1}\right)\right)^{+} \\
& +E\left[W_{2}\left(y_{1}+\xi_{1}\left(\tau_{1}\right)-D_{1}\right)\right] .
\end{aligned}
$$

And we have the following theorem.

Theorem 8. $H\left(y_{1}, \tau_{1}\right)$ in (28) is jointly convex in $y_{1}$ and $\tau_{1}$.

Proof. From part (a) in Theorem 4, we know that $W_{2}\left(i_{1}\right)$ is convex in $i_{1}$. And from Lemma $1, E\left[W_{2}\left(y_{1}+\xi_{1}\left(\tau_{1}\right)-D_{1}\right)\right]$ is jointly convex in $y_{1}$ and $\tau_{1}$.

From Theorem 3 , the cost function $E\left[g_{k}\left(i_{k-1}, \tau_{k}\right)\right]$ in (3) is convex in $i_{k-1}$ and $\tau_{k}$, so the function $E\left[g_{1}\left(0, y_{1}, \tau_{1}\right)\right]$ in (4) is also jointly convex in $y_{1}$ and $\tau_{1}$. Therefore, $H\left(y_{1}, \tau_{1}\right)$ in (28) is jointly convex in $y_{1}$ and $\tau_{1}$.
From Theorem 8, we can give the following form of the optimal policy at the first period.

Theorem 9. For the jointly inventory and the acquisition price decision problem at the first period, a policy $(S, \tau)$ is optimal.

Proof. Since $H\left(y_{1}, \tau_{1}\right)$ is jointly concave in $y_{1}$ and $\tau_{1}$, we have

$$
\begin{aligned}
& \min _{y_{1} \geq i_{0}, \tau_{1} \in\left[0, \tau^{u}\right]}\left\{H\left(y_{1}, \tau_{1}\right)\right\} \\
& =\min _{y_{1} \geq i_{0}}\left\{\min _{\tau_{1} \in\left[0, \tau^{u}\right]}\left\{H\left(y_{1}, \tau_{1}\right)\right\}\right\} .
\end{aligned}
$$

Obviously, there exists a unique $\tau_{1}\left(y_{1}\right)$ such that

$$
\tau_{1}\left(y_{1}\right)=\arg \min _{\tau_{1} \in\left[0, \tau^{u}\right]}\left\{H\left(y_{1}, \tau_{1}\right)\right\} .
$$

From Lemma 2, we know that $\min _{\tau_{1} \in\left[0, \tau^{u}\right]}\left\{H_{1}\left(y_{1}, \tau_{1}\right)\right\}$ is still convex in $y_{1}$. Therefore, the optimal final production order decision obeys a base-stock policy. And, furthermore, we can find the corresponding optimal inventory level $S$ such that $\left(S, \tau_{1}(S)\right)$ can minimize $H\left(y_{1}, \tau_{1}\right)$.

Theorem 9 shows that the optimal decisions at the first period follow a simple policy with two parameters. Executing the policy, the firm firstly reviews its initial inventory $i_{0}$ at the beginning of the planning horizon. Then, it determines the optimal base-stock level $S$. If the initial inventory level is less than the optimal basic-stock level $S$, then it replenishes the inventory of spare parts to $S$ and sets the optimal acquisition price level to be $\tau_{1}(S)$. If the initial inventory level is larger than the optimal basic-stock level $S$, then the firm does not need to replenish the spare-part inventory and set the optimal acquisition price level to be $\tau_{1}\left(i_{0}\right)$. For $\tau_{1}(S)$, we have the following property.

Theorem 10. $\tau_{1}(S)$ is decreasing with respect to the optimal inventory level $S$.

Proof. From the proof of part (c) in Theorem 4, we know that if $W_{k+1}\left(i_{k}\right)$ is convex, then $E\left[W_{k+1}\left(i_{k-1}+\xi_{k}\left(\tau_{k}\right)-D_{k}\right)\right]$ is supermodular in $i_{k-1}$ and $\tau_{k}$. From part (a) in Theorem 4, $W_{2}\left(i_{1}\right)$ is convex, so $E\left[W_{2}\left(y_{1}+\xi_{1}\left(\tau_{1}\right)-D_{1}\right)\right]$ is supermodular in $y_{1}$ and $\tau_{1}$.

From part (b) in Theorem $3, E\left[g_{1}\left(0, y_{1}, \tau_{1}\right)\right]$ is supermodular in $y_{1}$ and $\tau_{1}$. Furthermore, from $(28), H\left(y_{1}, \tau_{1}\right)$ is also supermodular in $y_{1}$ and $\tau_{1}$. Therefore, $\tau_{1}\left(y_{1}\right)$ is decreasing with respect to $y_{1}$. And $\tau_{1}(S)$ is decreasing with respect to S.

\section{Algorithm for Optimal Decisions}

Although the policy structure of the optimal acquisition pricing and the final production order are given in the above sections, the analytical forms of the related parameters in the policy structure are not obtained. In this section, we will give an algorithm to calculate the optimal decisions at each period. For convenience, we provide an algorithm description for the case of discrete state variables. 


\section{Algorithm 11.}

Step 1. Set $k=N+1$ and $W_{N+1}\left(i_{N}\right)=0$ for all $i_{N}$.

Step 2. Set $k \leftarrow k-1$.

Step 3. Find $X_{k}^{u}$ in (21) using the following judgement condition by a search algorithm (e.g., binary search method):

$$
\begin{aligned}
\frac{\partial H_{k}\left(i_{k-1}, \tau_{k}\right)}{\partial \tau_{k}}= & \beta h-q \beta+q \beta F\left(i_{k-1}+\alpha+\beta \tau_{k}\right)+\alpha \\
& +2 \beta \tau_{k} \\
& +\beta \frac{\partial E\left[W_{k+1}\left(i_{k-1}+\xi_{k}\left(\tau_{k}\right)-D_{k}\right)\right]}{\partial \tau_{k}}
\end{aligned}
$$

$>0$.

If $k=1$, then go to Step 4; otherwise, go to Step 3.1.

Step 3.1. Set $i_{k-1}=X_{k}^{u}$.

Step 3.2. Set $i_{k-1} \leftarrow i_{k-1}-1$, and find the solution $\tau_{k}^{\prime}$ of $\partial H_{k}\left(i_{k-1}, \tau_{k}\right) / \partial \tau_{k}=0$. If the solution $\tau_{k}^{\prime} \leq \tau^{u}$, then transfer to Step 3.3; otherwise, go to Step 3.4.

Step 3.3. Set $\tau_{k}^{*}\left(i_{k-1}\right)=\tau_{k}^{\prime}$, calculate $W_{k}\left(i_{k-1}\right)$ by the following equation, and then go to Step 3.2:

$$
W_{k}\left(i_{k-1}\right)=H_{k}\left(i_{k-1}, \tau_{k}^{*}\left(i_{k-1}\right)\right)
$$

Step 3.4. Set $\tau_{k}^{*}\left(i_{k-1}\right)=\tau^{u}$ and $X_{k}^{l}=i_{k-1}$, and go to the next step.

Step 3.5. Calculate $W_{k}\left(i_{k-1}\right)$. If $i_{k-1}=\operatorname{Min} i_{k-1}$ (the minimum value of system state), go to Step 2; otherwise, go to the next step.

Step 3.6. Set $i_{k-1} \leftarrow i_{k-1}-1$, set $\tau_{k}^{*}\left(i_{k-1}\right)=\tau^{u}$, and go to Step 3.5 .

Step 4. Set $y_{1}=X_{1}^{u}$ and calculate $W_{1}\left(y_{1}\right)$; let $H$ Min Val $=$ $W_{1}\left(y_{1}\right)$ and $S=y_{1}$.

Step 4.1. Set $y_{1} \leftarrow y_{1}-1$, and find the solution $\tau_{1}^{\prime}$ of $\partial H_{1}\left(i_{0}, \tau_{1}\right) / \partial \tau_{1}=0$. If the solution $\tau_{1}^{\prime} \leq \tau^{u}$, then go to Step 4.2; otherwise, go to Step 4.3.

Step 4.2. Set $\tau_{1}^{*}\left(y_{1}\right)=\tau_{1}^{\prime}$, and calculate $W_{1}\left(y_{1}\right)$. If $W_{1}\left(y_{1}\right)<$ $H$ Min Val, then set $H$ Min Val $=W_{1}\left(y_{1}\right)$ and $S=y_{1}$, and go to Step 4.1 .

Step 4.3. Set $\tau_{1}^{*}\left(y_{1}\right)=\tau^{u}$ and $X_{1}^{l}=y_{1}$, and go to Step 4.4.

Step 4.4. Calculate $W_{1}\left(y_{1}\right)$. If $W_{1}\left(y_{1}\right)<H$ Min Val, then set $H$ Min Val $=W_{1}\left(y_{1}\right)$ and $S=y_{1}$, and go to Step 4.5.

Step 4.5. Set $y_{1} \leftarrow y_{1}-1$ and $\tau_{1}^{*}\left(y_{1}\right)=\tau^{u}$, and go to Step 4.4.

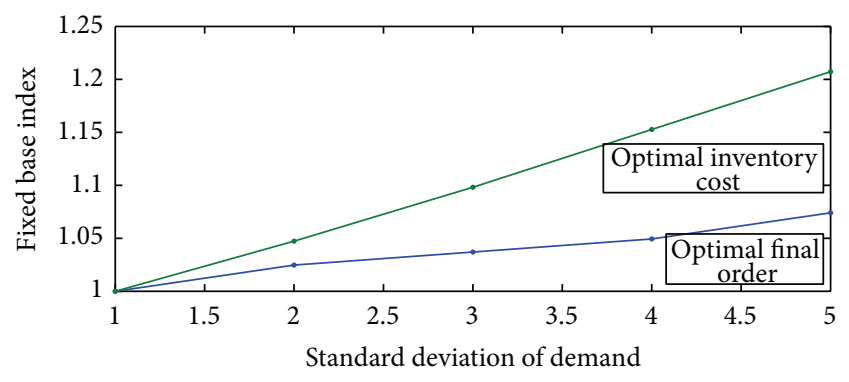

FIGURE 1: Effects on optimal final order and inventory cost.

\section{Numerical Study}

By some advanced information technologies (such as Wireless Communication Networks, Radio-Frequency Identification (RFID), cloud computing, etc.), one enterprise might obtain more information on the using products or the customers of holding used products. To analyze the effect of those information on the inventory policy parameters (including $X_{k}^{l}, X_{k}^{u}$, and $S$ ) and the optimal operation cost of the spare-part system, we will adjust parameters to obtain those trends by numerical ways in this section. We mainly consider the effects of two parameters: one is the standard deviation of the uncertain demand at each period, and the other is the customer's sensitive degree on the acquisition price.

We give a basic setting of related parameters. The demand is assumed to follow a normal distribution with the mean 20 and the standard deviation 2, and the disturbance variable $\varepsilon$ of the return quantity follows a normal distribution with zero mean and the standard deviation 0.2 . The other parameters are given as follows: $N=5, \alpha=4, \beta=1, h=1$, and $q=30$.

6.1. Effect of the Demand Uncertainty. Firstly, we investigate the effects of the uncertainty of the period demand on the optimal final production order, pricing bounds in the above pricing policy structure, and the optimal inventory cost. Let the standard deviation of the uncertain period demand vary from 1 to 5 ; the fixed base indexes of optimal final production orders and the system optimal costs can be shown in Figure 1, where the fixed bases are the optimal production final orders and the system optimal cost in the first period.

From Figure 1, we know that, as the increasing of the standard deviation, both the optimal final order $S$ and the system optimal cost are also increasing. Because the improvement of the demand uncertainty will make the increasing of the shortage cost larger than the increasing of the inventory holding cost, therefore, the optimal inventory level will be improved, and the corresponding optimal cost of the system is also increasing.

From Figure 2, we know that the bounds $X_{k}^{u}$ and $X_{k}^{l}$ are decreasing with respect to the increasing of the period number $k$. The upper bound means the critical point which the system does not need to acquire used products, and the lower bound means the critical point which the system needs to acquire used products as possible. If the enterprise 
TABLE 1: Period bounds under different standard deviations.

\begin{tabular}{lccccc}
\hline Sta. dev. & Bounds & Period 2 & Period 3 & Period 4 & Period 5 \\
\hline \multirow{2}{*}{1} & Lower bound & 44 & 33 & 23 & 11 \\
& Upper bound & 63 & 48 & 33 & 17 \\
\hline \multirow{2}{*}{2} & Lower bound & 45 & 34 & 23 & 11 \\
& Upper bound & 63 & 49 & 34 & 18 \\
\hline \multirow{2}{*}{3} & Lower bound & 47 & 34 & 23 & 11 \\
& Upper bound & 64 & 49 & 35 & 19 \\
\multirow{2}{*}{4} & Lower bound & 47 & 35 & 24 & 11 \\
& Upper bound & 65 & 50 & 36 & 20 \\
\hline \multirow{2}{*}{5} & Lower bound & 47 & 35 & 25 & 12 \\
& Upper bound & 66 & 51 & 37 & 21 \\
\hline
\end{tabular}

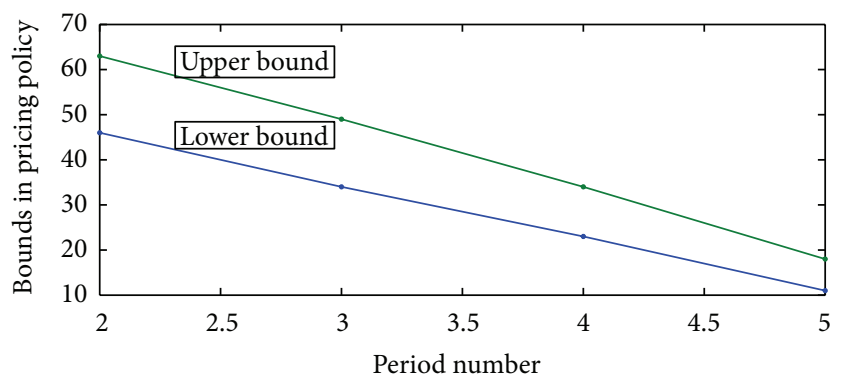

FIGURE 2: Period index on bounds in pricing policy.

faces a larger uncertainty within a longer future planning horizon, which will make the increasing of the shortage cost larger than the increasing of the inventory holding cost, the whole inventory holding level should be increased. When the number $k$ is little, the enterprise needs to pay more attention for dealing with the future longer and larger uncertain demand, so both critical points of acquiring and not acquiring used products should be increased. And with respect to the decreasing of the planning length, the fluctuation between upper bound and lower bound is decreasing because the fluctuation of the future demand is decreasing.

From Table 1, we know that, as the increasing of the standard deviation, both bounds $X_{k}^{u}$ and $X_{k}^{l}$ are increasing. The results are similar to the above properties: the critical point of holding inventory level also will be increased when the enterprise faces the larger uncertainty.

6.2. Effect of the Return Sensitivity. In this subsection, we will investigate the effects of the return sensitivity.

From Figure 3, as the increasing of the return sensitivity degree, the optimal final production order $S$ is decreasing, and the optimal inventory cost is also decreasing. The same acquisition price will acquire more used products than that for the case with little return sensitivity, and the enterprise does not need to hold a higher safety inventory if the product acquisition is more easy, so there are the results in Figure 3.

From Table 2, as the increasing of the return sensitivity degree, both bounds $X_{k}^{u}$ and $X_{k}^{l}$ are decreasing. The reasons of the results are similar to the reason for Figure 3: when the acquisition way is more effective, the enterprise does not need
TABLE 2: Period bounds under different return sensitivities.

\begin{tabular}{lccccc}
\hline $\begin{array}{l}\text { Sensitivity } \\
\text { degree }\end{array}$ & Bounds & Period 2 & Period 3 & Period 4 & Period 5 \\
\hline \multirow{2}{*}{1} & Lower bound & 46 & 34 & 23 & 11 \\
& Upper bound & 63 & 49 & 34 & 18 \\
\hline \multirow{2}{*}{1.5} & Lower bound & 33 & 24 & 16 & 8 \\
& Upper bound & 60 & 48 & 33 & 19 \\
\hline \multirow{2}{*}{2} & Lower bound & 27 & 20 & 13 & 6 \\
& Upper bound & 60 & 47 & 33 & 19 \\
\hline \multirow{2}{*}{2.5} & Lower bound & 17 & 12 & 8 & 4 \\
& Upper bound & 58 & 46 & 33 & 19 \\
\hline \multirow{2}{*}{3} & Lower bound & 9 & 7 & 5 & 1 \\
& Upper bound & 57 & 46 & 33 & 19 \\
\hline
\end{tabular}

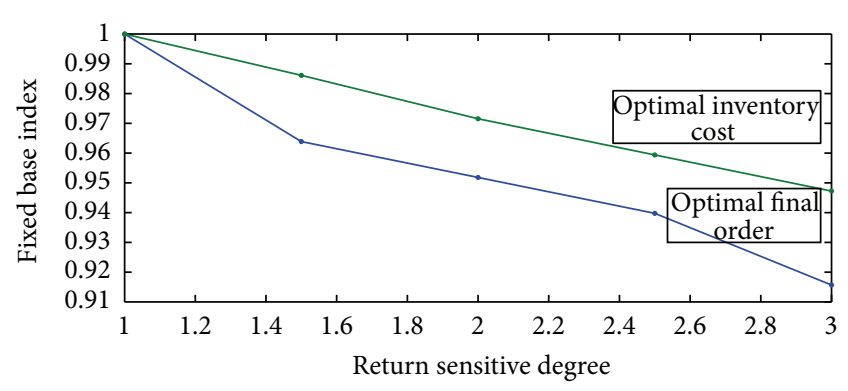

FIGURE 3: Effects on optimal final order and inventory cost.

to hold a higher inventory. The critical points of acquiring and not acquiring used products can be decreased.

\section{Conclusion}

In order to gain a competitive advantage in an increasing competitive market, many enterprises have improved the concerning for the after-sale service in a regular warranty period. However, the service within the warranty period is not enough for maintaining the customer's satisfaction, which is showed by Nagler [1]: "you buy a car and eight years later cannot get it serviced for a reasonable price because the manufacturer has discontinued a particular part, you will remember it when you buy your next vehicle". Therefore, in addition to the regular warranty period, the service outside the warranty period is also important. The traditional ways of replenishing spare parts within the warranty period include the final production order and the additional production, but those are higher cost or setup cost, especially for durable products outside the warranty period.

In this paper, we consider two ways including the final production order and remanufacturing. the remanufacturing way has been concerned in recent years, but few papers consider the acquisition management problem of used products in an inventory system with remanufacturing. We assume that the returning process is controlled by the acquisition price of used products and consider a multiperiod dynamic optimization problem, where the system decisions include 
the optimal final production batch size and the optimal acquisition price at each period. In order to obtain the optimal policy, we divided our analysis into two stages. First, we study the optimal acquisition pricing from the second period to final period. By stochastic dynamic programming, we prove the structural properties of the objective function and give an optimal monotonous pricing with key thresholds. Then, we analyze the optimal decision problem at the first period, which is jointly an inventory and pricing problem, and we prove a simple policy $(S, \tau)$ to be optimal. Furthermore, we propose a recursion algorithm and make some numerical examples.

In the future, the combination of more replenishment ways can be considered in one framework, which may include the final production order, extra production, substitution, and remanufacturing. Certainly, the acquisition pricing should be considered. The other direction is to consider a closed-loop structure; that is, the return of used products is dependent on the historic demands, which will be a more attractive perspective.

\section{Notations}

$N$ : Total number of all running periods

$h$ : Inventory holding cost of per unit component in one period

$q$ : $\quad$ Penalty cost of per unit inventory shortage

$\tau^{u}: \quad$ Maximum acquisition price

$\tau_{k}: \quad$ Acquisition price at the period $k, 1 \leq k \leq N$, $\tau_{k} \in\left[0, \tau^{u}\right]$

$D_{k}$ : Demand of the spare part at period $k, 1 \leq k \leq N$, which is a stochastic variable

$\xi_{k}\left(\tau_{k}\right)$ : Returned quantity when the acquisition price is $\tau_{k}$, $1 \leq k \leq N$, which is a stochastic variable with the form $\xi_{k}\left(\tau_{k}\right)=\mu_{k}\left(\tau_{k}\right)+\varepsilon_{k}$, where $\varepsilon_{k}$ is a random factor with support $\left[a_{k}, b_{k}\right]$ and zero mean value and the probability density function $f(\cdot)$ and the cumulative distribution function $F(\cdot)$

$I_{k}: \quad$ Inventory level at the end of period $k$

$i_{0}$ : Initial inventory level at the beginning of the planning horizon.

\section{Competing Interests}

The authors declare that there are no competing interests regarding the publication of this paper.

\section{Acknowledgments}

This research is supported by National Natural Science Foundation of China (NSFC), Research Fund no. 71302112.

\section{References}

[1] B. Nagler, "Reintroducing remanufacturing," Machine Design, vol. 71, no. 22, pp. 78-84, 1999.

[2] M. J. Armstrong and D. R. Atkins, "Joint optimization of maintenance and inventory policies for a simple system," IIE Transactions, vol. 28, no. 5, pp. 415-424, 1996.
[3] W. Bruggeman and R. van Dierdonck, "Maintenance resource planning an integrative approach," Engineering Costs and Production Economics, vol. 9, no. 1-3, pp. 147-154, 1985.

[4] T. S. Dhakar, C. P. Schmidt, and D. M. Miller, "Base stock level determination for high cost low demand critical repairable spares," Computers \& Operations Research, vol. 21, no. 4, pp. 411420, 1994.

[5] A. Díaz and M. C. Fu, "Models for multi-echelon repairable item inventory systems with limited repair capacity," European Journal of Operational Research, vol. 97, no. 3, pp. 480-492, 1997.

[6] M. Fleischmann, J. A. E. E. van Nunen, and B. Gräve, "Integrating closed-loop supply chains and spare-parts management at IBM," Interfaces, vol. 33, no. 6, pp. 44-56, 2003.

[7] R. H. Teunter and L. Fortuin, "End-of-life service: a case study," European Journal of Operational Research, vol. 107, no. 1, pp. 1934, 1998.

[8] L. Fortuin, "The all-time requirement of spare parts for service after salestheoretical analysis and practical results," International Journal of Operations \& Production Management, vol. 1, no. 1, pp. 59-70, 1980.

[9] R. H. Teunter and L. Fortuin, "End-of-life service," International Journal of Production Economics, vol. 59, no. 1, pp. 487-497, 1999.

[10] K. D. Cattani and G. C. Souza, "Good buy? Delaying end-of-life purchases," European Journal of Operational Research, vol. 146, no. 1, pp. 216-228, 2003.

[11] J. P. J. van Kooten and T. Tan, “The final order problem for repairable spare parts under condemnation," Journal of the Operational Research Society, vol. 60, no. 10, pp. 1449-1461, 2009.

[12] R. H. Teunter and W. K. Klein Haneveld, "Inventory control of service parts in the final phase," European Journal of Operational Research, vol. 137, no. 3, pp. 497-511, 2002.

[13] K. Inderfurth and K. Mukherjee, "Decision support for spare parts acquisition in post product life cycle," Central European Journal of Operations Research, vol. 16, no. 1, pp. 17-42, 2008.

[14] M. Pourakbar, J. B. G. Frenk, and R. Dekker, "End-of-life inventory decisions for consumer electronics service parts," Work Paper, Erasmus School of Economics, Erasmus University Rotterdam, Rotterdam, The Netherlands, 2009.

[15] K. E. Bourland, S. G. Powell, and D. F. Pyke, "Exploiting timely demand information to reduce inventories," European Journal of Operational Research, vol. 92, no. 2, pp. 239-253, 1996.

[16] G. Gallego and Ö. Özer, "Integrating replenishment decisions with advance demand information," Management Science, vol. 47, no. 10, pp. 1344-1360, 2001.

[17] G. Gallego and Ö. Özer, "Optimal replenishment policies for multiechelon inventory problems under advance demand information," Manufacturing and Service Operations Management, vol. 5, no. 2, pp. 157-175, 2003.

[18] Ö. Özer and W. Wei, "Inventory control with limited capacity and advance demand information," Operations Research, vol. 52, no. 6, pp. 988-1000, 2004.

[19] S. Axsater, Inventory Control, Springer, Berlin, Germany, 2006.

[20] A. Federgruen and A. Heching, "Combined pricing and inventory control under uncertainty," Operations Research, vol. 47, no. 3, pp. 454-475, 1999.

[21] D. Simchi-Levi, X. Chen, and J. Bramel, The Logic of Logistics: Theory, Algorithms and Applications for Logistics and Supply Chain Management, Springer, New York, NY, USA, 2nd edition, 2004 
[22] X. Sun, Y. Li, K. Govindan, and Y. Zhou, "Integrating dynamic acquisition pricing and remanufacturing decisions under random price-sensitive returns," International Journal of Advanced Manufacturing Technology, vol. 68, no. 1-4, pp. 933-947, 2013.

[23] S. Boyd and L. Vandenberghe, Convex Optimization, Cambridge University Press, Cambridge, Mass, USA, 2004.

[24] S. M. Ross, Stochastic Processes, John Wiley \& Sons, New York, NY, USA, 2nd edition, 1996.

[25] M. L. Puterman, Markov Decision Processes: Discrete Stochastic Dynamic Programming, John Wiley \& Sons, New York, NY, USA, 1994. 

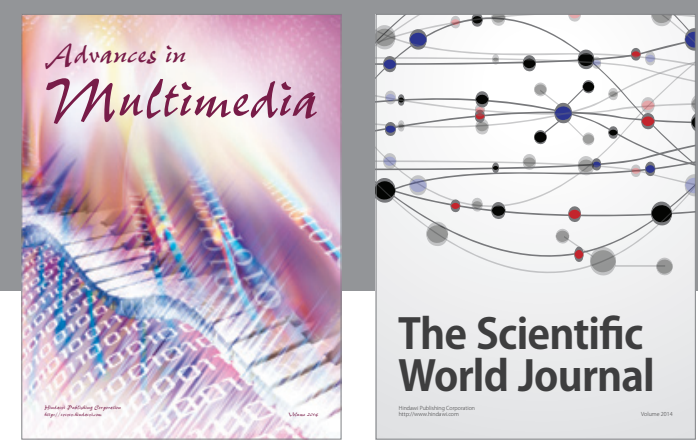

The Scientific World Journal


Submit your manuscripts at

http://www.hindawi.com

\section{Computer Networks} and Communications
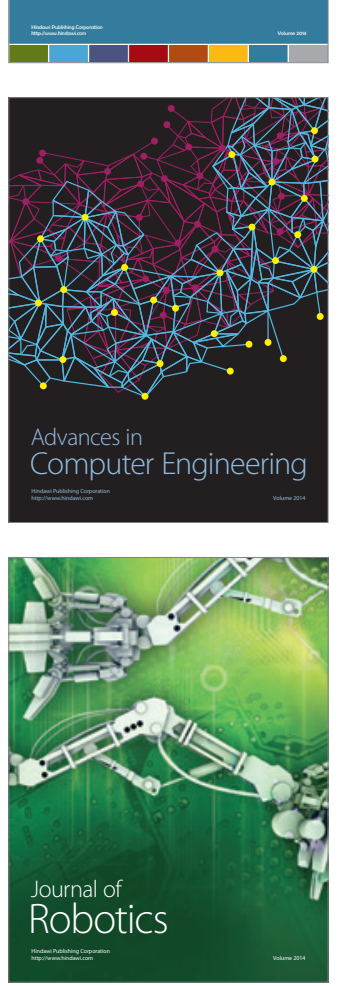
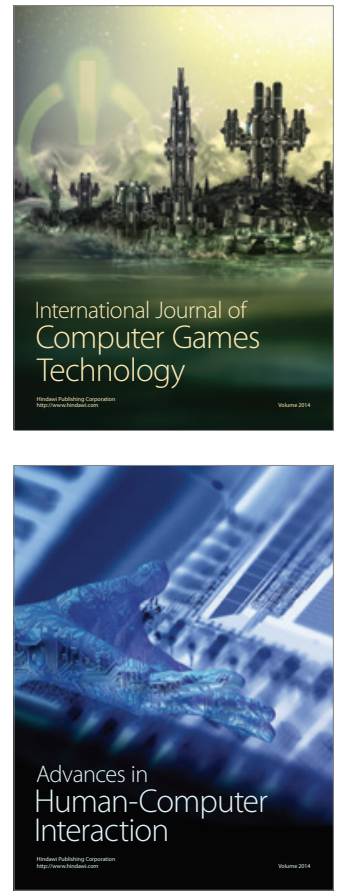
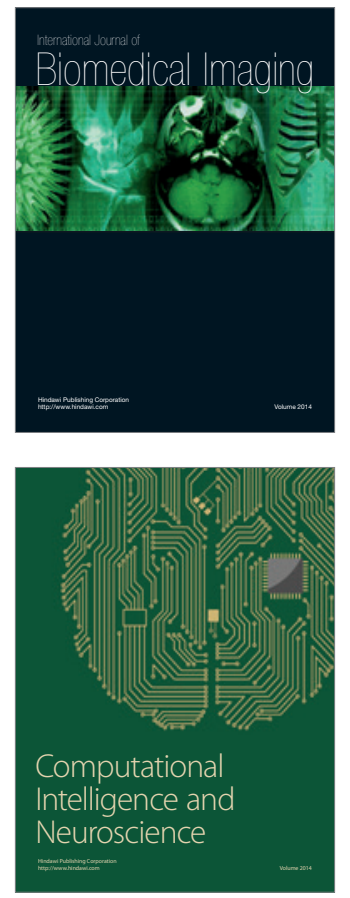

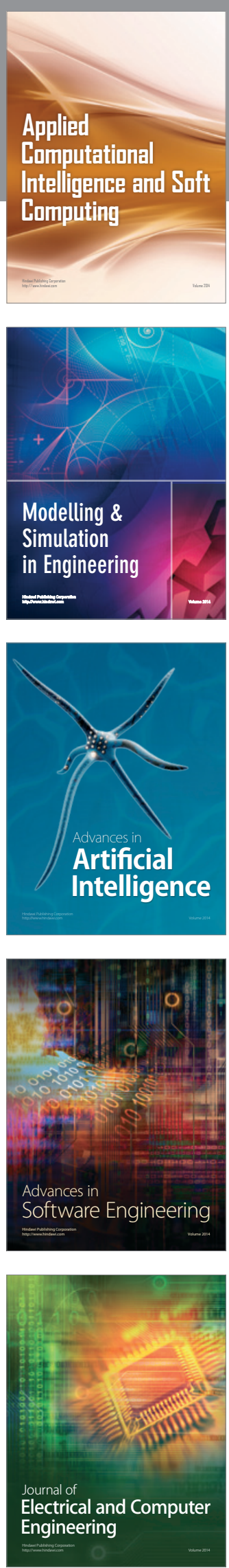